\title{
Dynamics of diffusion jet combustion in an ejection burner
}

\author{
Oleg Evdokimov ${ }^{1, *}$, Alexander Guryanov ${ }^{1}$, Sergey Veretennikov $^{1}$, and Marina Guryanova ${ }^{1}$ \\ ${ }^{1}$ Rybinsk State Aviation Technical University named after P.A.Soloviev, 152934 Rybinsk, Russian \\ Federation
}

\begin{abstract}
In this work we present the results of computational and experimental studies on the burnout dynamics of diffusion gas jets in an ejection burner with a two-stage air ejection scheme. It is shown that usage of this scheme leads to an increase in the uniformity of the distribution of thermogasdynamic parameters at the burner outlet, an increase in the completeness of combustion of the fuel, and a more stable operation of the device.
\end{abstract}

\section{Introduction}

The development of the gas industry has led to the creation of gas burners of various types, some of which are fairly widespread in the energy, aviation, construction and housing and utilities sectors [1-5].

Usage of large amounts of fuel of various aggregative states in the national economy and industry requires development, testing and implementation of the most advanced gas combustion technology, as well as creation of new highly efficient, multifunctional gas burners and improvement of the existing structures [5].

Among practical combustion schemes for hydrocarbon fuels, along with catalytic and surface burning, the organization of diffusion and pre-mixed reactive gas jets is widespread. In technical applications, reactive diffusion jets are used: in the combustion chambers of heat and power boilers of various power classes; high-temperature technological process of heating, melting, drying and heat treatment of surfaces; associated gas combustion technologies in hydrocarbon fields; multi-flare burners of combustion chambers of condensing boilers of distributed energy [6-22]. The diffusion mechanism of flame propagation underlies the formation of forest and man-made fires.

The results of research available in literature show that a significant optimization of the working process of diffusion burners and an improvement of their characteristics can be achieved through the use of ejection schemes for the supply of oxidant to the combustion zone [23-27]. At the same time, the conditions of the organization of the ejection process determine the possibility of providing a more uniform temperature field at the burner exit, cooling the walls of the flame tube, increasing the combustion efficiency of the fuel and extending the range of stable operation in terms of thermal power. From this point of view,

\footnotetext{
*Corresponding author: yevdokimov_oleg@mail.ru
} 
a two-stage scheme of ejection of air into the combustion zone seems promising. The burner device implementing the marked scheme is shown in Fig. 1. When the burner is operating, the active stream is the jet of fuel flowing into the volume of the mixing chamber, and the air ejected from the atmosphere through the two contours of the purge holes forms a passive (ejected) stream. Burners of this type with a single-stage oxidant feed are widely used in high-temperature technologies for cleaning surfaces from pollution, construction, and agriculture [23-27].

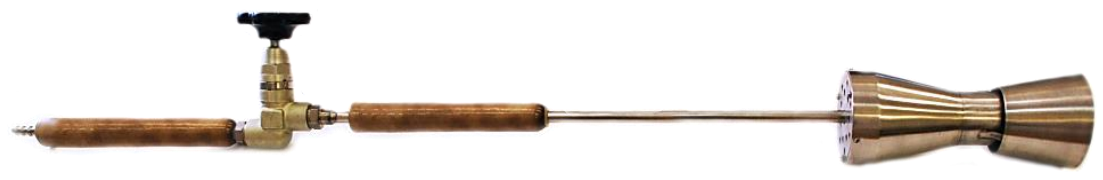

Fig. 1. The burner device with two-stage ejection of air.

\section{Methods}

\subsection{Numerical Model}

The scheme of the burner under investigation is shown in Figure 2. The flow part of the device consists of confuser, cylindrical and diffuser sectors, the main feature of the module is usage of a two-stage air supply circuit. A fuel injector is installed on the axis of the burner module, which forms the diffusion zone of combustion during oxidation by air masses coming from the holes in the end plate. In the area of the diffuser section, the combustible mixture is diluted to the required value of the excess air coefficient and the afterburning zone of the fuel is formed.

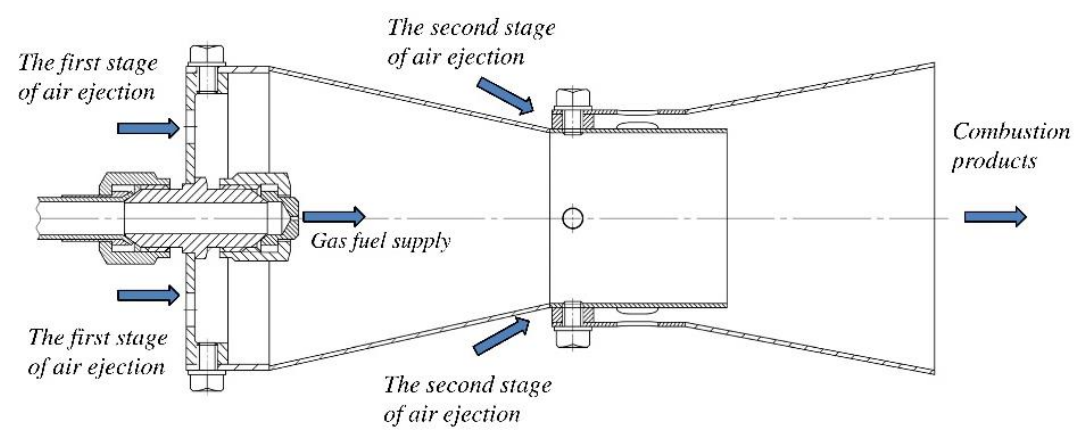

Fig. 2. The scheme of the burner device with two-stage ejection of air.

To perform the research, a block computational grid per sector torch model $\left(90^{\circ}\right)$ with 1.5 million junctions was generated (Fig. 3). The simulated area consists of the flow-through part of the burner module and an additional section of the combustion, limited by a cylindrical wall. When performing numerical simulations, the RANS approach was used using the SST model of turbulence, and the conditions of "sticking" and adiabaticity of the burner walls were specified. The boundary conditions of the calculation are shown in Table 1, and the scheme of their imposition in the calculation area is shown in Fig. 4. 
Table 1. Boundary conditions for modeling the burner module.

\begin{tabular}{|c|c|c|c|}
\hline No. & Boundary conditions & Consumption/Pressure & $\begin{array}{c}\text { Total } \\
\text { temperature }\end{array}$ \\
\hline 1 & $\begin{array}{c}\text { Fuel parameters at the inlet to the } \\
\text { burner module, } G_{\text {gas }}, T^{*} \text { gas }\end{array}$ & $0.0001-0.001 \mathrm{~kg} / \mathrm{s}$ & $300 \mathrm{~K}$ \\
\hline 2 & $\begin{array}{c}\text { Air parameters at the inlet to the } \\
\text { first stage of supply, } p^{*}{ }_{\text {airl }}, T^{*}{ }_{\text {air }}\end{array}$ & $101325 \mathrm{~Pa}$ & $300 \mathrm{~K}$ \\
\hline 3 & $\begin{array}{c}\text { Air parameters at the inlet to the } \\
\text { second stage of supply, } p^{*}{ }_{\text {air2 }}, T^{*}{ }_{\text {air }}\end{array}$ & $101325 \mathrm{~Pa}$ & $300 \mathrm{~K}$ \\
\hline 4 & $\begin{array}{c}\text { Parameters of the opening and } \\
\text { mixture at the outlet of the } \\
\text { simulated area, } p_{\text {out }}, T^{*}{ }_{\text {out }}\end{array}$ & $100000 \mathrm{~Pa}$ & $300 \mathrm{~K}$ \\
\hline
\end{tabular}

The kinetics of chemical reactions was simulated using the kinetic scheme of propane combustion, which includes four elementary intermediate reactions. Eddy Dissipation Model (EDM) was used to describe the combustion mechanism.

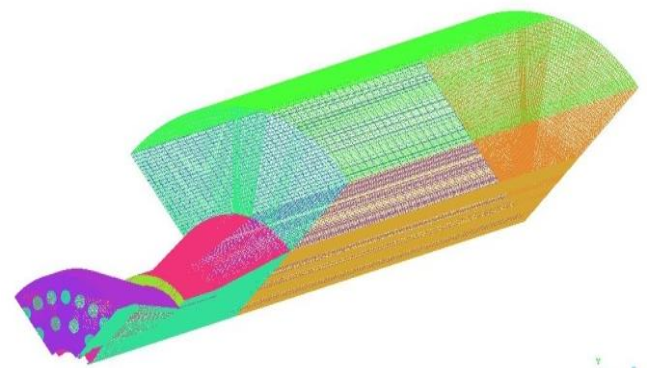

Fig. 3. Computational grid.

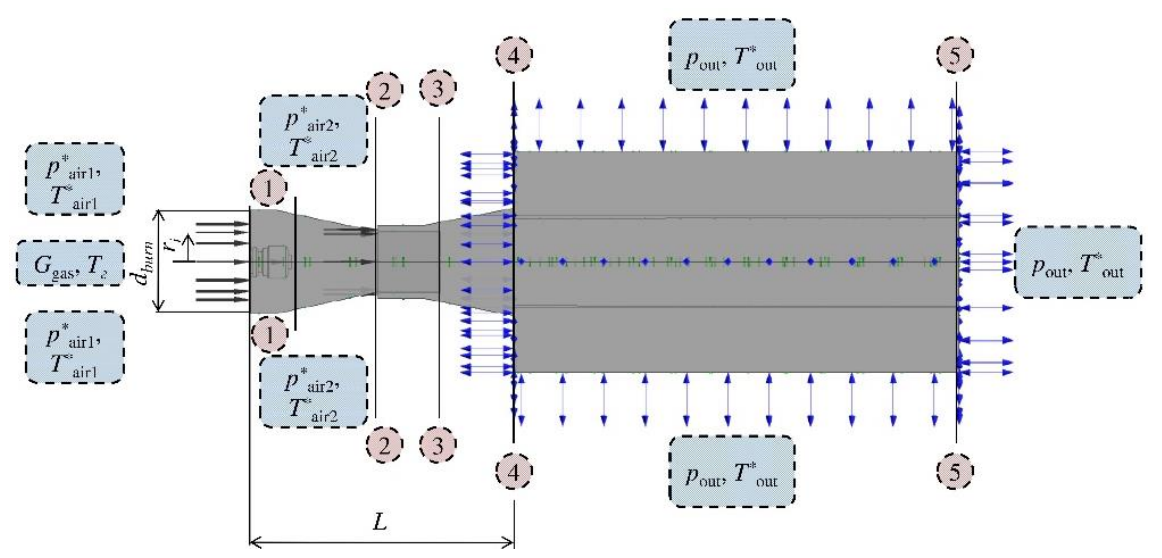

Fig. 4. The scheme for boundary conditions and location of the typical sections $(1,2,3,4,5)$ at the simulated area of the burning module. 


\subsection{Experimental Setup}

For carrying out experimental studies of an ejection burner, we assembled a test stand, the scheme of which is shown in Fig. 5. During our experiments, the following parameters were measured and calculated:

- Mass consumption of fuel at the burner inlet, $G_{\text {gas; }}$;

- Total pressure of fuel at the burner inlet, $p^{*}$ gas;

- Total temperature of fuel at the burner inlet, $T^{*}$ gas;

- Total temperature at the combustion zone, $T^{*}$ comb;

- Concentration of the hydrocarbons $C_{\mathrm{CxHy}}$, oxygen $C_{\mathrm{O} 2}$, nitrogen $C_{\mathrm{N} 2}$, carbon monoxide $C_{\mathrm{CO}}$, carbon dioxide $C_{\mathrm{CO} 2}$, water vapours $C_{\mathrm{H} 2 \mathrm{O}}$, nitrogen oxides $C_{\mathrm{NOx}}$ in typical sections of the combustion zone.

- Nominal thermal power, $N$;

- Efficiency of fuel combustion, $\eta$;

- The length of fuel burnout zone, $l_{\text {comb }}$ (at $\left.\eta=0.995\right)$;

- Volume of the combustion zone, $V_{\text {comb. }}$

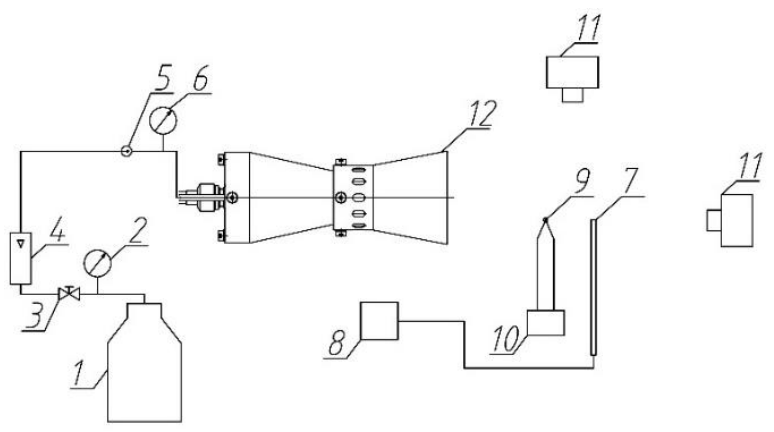

Fig. 5. Functional scheme of the experimental stand: 1 - fuel tank; 2,6 - total pressure meter; 3 -control valve; 4 - mass flow meter; 5 - chromel-copel thermocouple; 7 - gas sample probe; 8 - gas analyzer; 9 - platinum-rhodium thermocouple; 10 - digital receiver; 11 - photocamera; 12 - burning device.

\section{Results and Discussion}

Figure 6 shows the distribution of the total velocity and the profiles of its axial component in the typical sections of the burner module, marked in Figure 4.

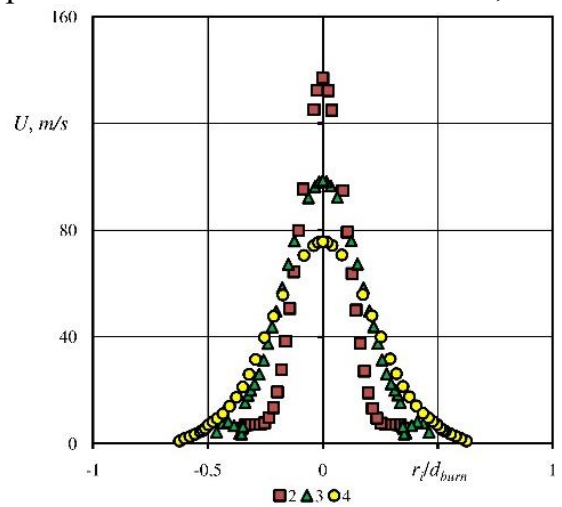

(a)

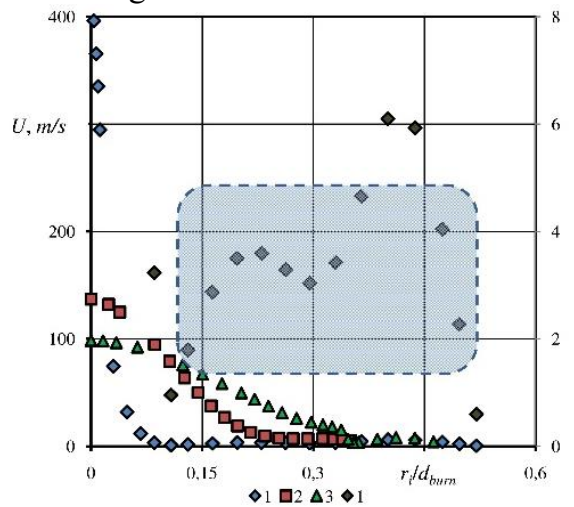

(b)

Fig. 6. Distribution of the total velocity (a) and axial component of velocity (b) in the corresponding sections of flow section of the burner module. 
Fuel is supplied to the mixing zone under a pressure of $0.6 \mathrm{MPa}$. The supercritical pressure drop causes the outflow of the fuel jet from the nozzle at a speed of $M \approx 1$. This leads to the formation of an ejecting submerged jet, the core of which retains the individual structure to a relative length $1_{i} / d_{\text {burn }}=2.45$. In this case, the peripheral mixing layer, due to the radial transfer of the pulse, ejects air masses which enter the mixing zone through the cylindrical holes in the end wall of the module. The speed of their flowing into the flow part of the device is chosen from the condition required to ensure the heat output of $50 \mathrm{~kW}$ of air flow and the minimum loss of total pressure when the jet is expanded and the flows are mixed. In the region of the aerodynamic boundary of the submerged jet, a mixing layer is formed, the local value of the coefficient of excess air in which is close to $\alpha=1$.

The obtained results show that gas-dynamic conditions of flame stabilization are formed in the mixing layer. In Figure 6 (b) they are shown by a dashed rectangle with a reference on the secondary axis of ordinates. In these local volumes, the combustion process begins, as evidenced by a corresponding increase in temperature, the maximum value of which repeats the profile of the combustion wave stabilized by stoichiometric volumes in the aerodynamic mixing layer of the active and passive flows (Figure 7).

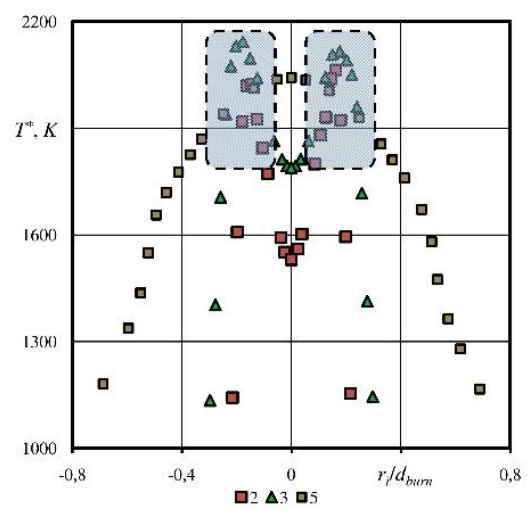

Fig. 7. Distribution of the total temperature in transversal sections of the flowing part of the burning device.

Figure 8 shows distributions of the concentrations of fuel, oxygen, products of complete combustion $(\mathrm{CO} 2)$ and intermediate products of the reaction $(\mathrm{CO})$ in typical sections of the burning device.

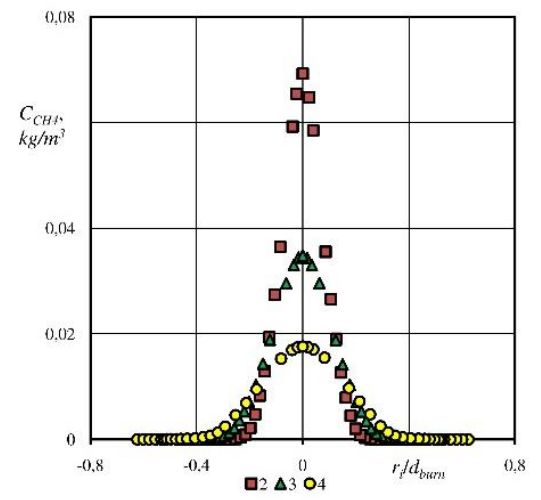

(a)

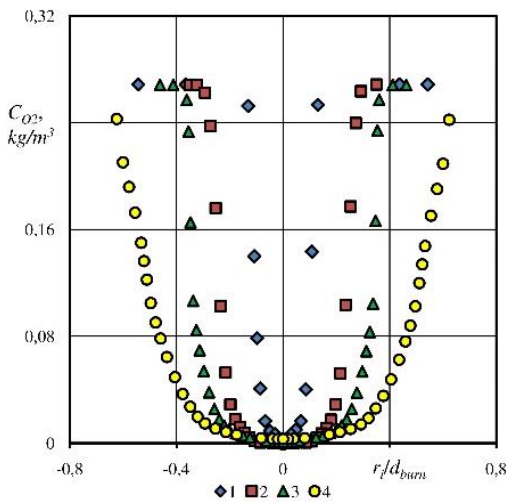

(b) 


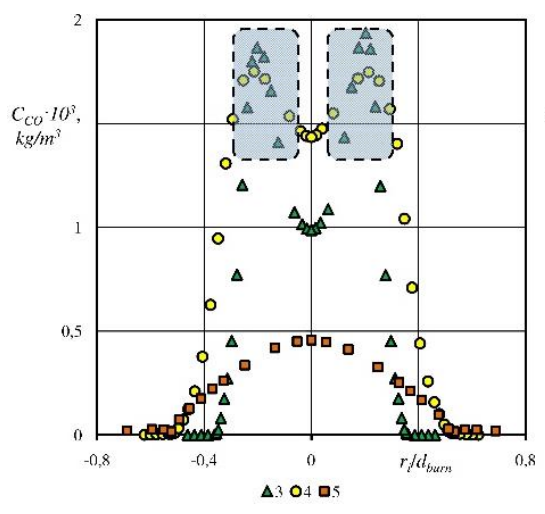

(c)

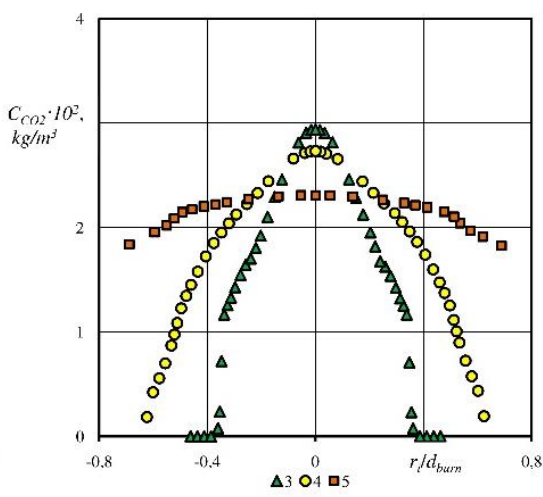

(d)

Fig. 8. Distribution of concentrations of $\mathrm{C} 3 \mathrm{H} 8$ (a), $\mathrm{O} 2$ (b), $\mathrm{CO}$ (c) and $\mathrm{CO} 2$ (d) in transversal sections of the flowing part of the burner.

The mass concentrations of all the listed components are uniquely related. It can be seen that local fuel-rich gas volumes in the axial region of the mixing chamber with concentration $\alpha \rightarrow 0$, when diluted with oxygen and approaching stoichiometry $(\alpha \sim 1)$, react chemically with a corresponding decrease in the mass fraction of fuel and oxidizer and appearance of products of complete combustion.

Figure 8 (d) shows that almost the entire mass of the $\mathrm{CO} 2$ produced is concentrated in the paraxial region of the flame of the combustion products, causing the "pushing" of the secondary reaction wave in the radial direction with increasing relative length. The clearest visualization of the flame front geometry is provided by the distribution of intermediate reaction products over the volume of the combustion zone. In the absence of developed recirculation zones and return flows in the flow field, there is a separation of unburned components and products of complete combustion with a thin surface consisting mainly of intermediate products, and in particular CO (Figure 8 (c)).

The presented distributions of mass concentrations of products of complete and incomplete combustion determine the type of burnout curve of fuel along the length of the torch. Figure 9 (a) shows the dependencies for the following modes for nominal heat output: $\mathrm{N}=10 \mathrm{~kW}, \mathrm{~N}=25 \mathrm{~kW}, \mathrm{~N}=50 \mathrm{~kW}$. The points on the graph are obtained as a result of averaging the local values of the completeness of combustion over selected cross sections of the combustion zone at different distances from the region of the initial initiation of the reaction wave.

It can be seen that when the nominal heat output changes from $\mathrm{N}=10 \mathrm{~kW}$ to $\mathrm{N}=50 \mathrm{~kW}$, by increasing the fuel consumption through the nozzle, the combustion efficiency in the output section of module 4 decreases from $\eta=0.866$ to $\eta=0.792$.

It should be noted that the regions of the flow part of the burner module, in which combustion conditions close to stoichiometric are formed, and characterized by maximum temperatures (Figure 7), have a toroidal shape, radially limited to $0.15 \leq r_{\mathrm{i}} / d_{\text {burn }} \leq 0.25$ (marked by dotted rectangles in Figures 7,8 (c)). In this case, the values of Reynolds numbers calculated from the corresponding equivalent diameters of these areas will vary in the ranges of $66860 \leq \mathrm{Re} \leq 93600$ for $\mathrm{N}=50 \mathrm{~kW}$ and $16800 \leq \mathrm{Re} \leq 23500$ for $\mathrm{N}=10 \mathrm{~kW}$ corresponding to the turbulent flow regime.

Figure 9 (b) shows the change in the volume of complete burnout of the mixture, related to the volume of the burner $(\eta>0.995)$ depending on the power of the device. 


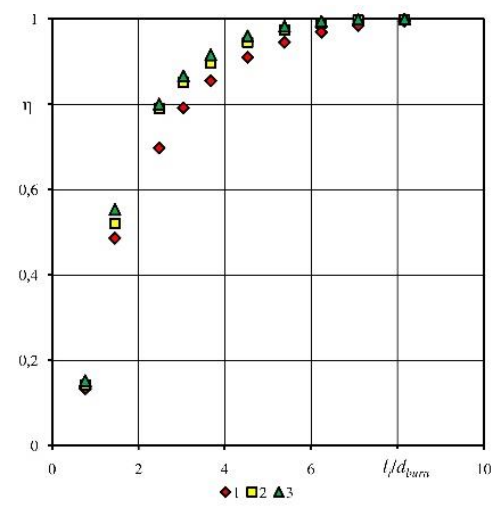

(a)

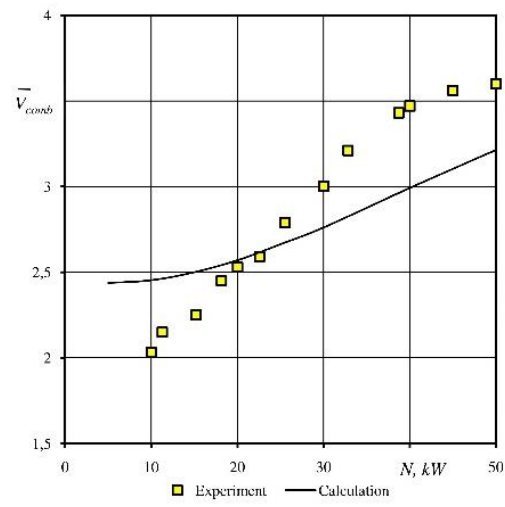

(b)

Fig. 9. (a) Burnout curves for modes of rated heat output: $1-\mathrm{N}=10 \mathrm{~kW}, 2-\mathrm{N}=10 \mathrm{~kW}, 3-\mathrm{N}=10 \mathrm{~kW}$; (b) Dependence of the volume of complete burnout of the mixture on the power of the burner module.

It is seen from the graph that an increase in the nominal thermal power of the burner module leads to an increase in the volume of the oxidation reaction zone and this curve has an upward character. Such behavior of the function $V_{\text {comb }}=f(N)$ is also qualitatively confirmed by the results of numerical simulation of the combustion process, the relative deviation of which from the experimental data reaches $17 \%$.

\section{Conclusions}

The performed computational and experimental studies have shown that organization of a two-stage scheme for the ejection of air into the combustion zone of the device allows one to provide high uniformity of the distribution of the thermodynamic parameters in its output section. The constructed dependences of the completeness of combustion of fuel along the length of the burner device state for the high efficiency of its operating process in the range of thermal power of $10-50 \mathrm{~kW}$.

This work was financially supported by RSF (Russian Science Foundation) grant No. 18-79-00180 "Thermophysics of combined reacting jets and impact flows."

\section{References}

1. M. Khosravy, Progress in Gas Turbine Performance (2013), DOI: 10.5772/54403

2. S.S. Rashwan, M.A. Nemitallah, M.A. Habib, Energy Fuels, 30, 9981 (2016), DOI: 10.1021/acs.energyfuels.6b02386

3. Y. Liu, X. Sun, V. Sethi, D. Nalianda, Y.G. Li, L. Wang, Prog. Aerosp. Sci., 94, 12 (2017), DOI: 10.1016/j.paerosci.2017.08.001

4. Y. Ju, K. Maruta, Prog. Energ. Combust., 37, 669 (2011), DOI: 10.1016/j.pecs.2011.03.001

5. A.I. Guryanov, O.A. Evdokimov, S.V. Veretennikov, M.M. Guryanova, Int. J. Ener. Clean Env., 18, 335 (2017), DOI: 10.1615/InterJEnerCleanEnv.2018021223

6. P.P.J. Stroomer, J.E. de Vries, Th.H. van der Meer, Flow. Turbul. Combust., 62, 53 (1999)

7. F. Nmira, D. Burot, J.-L. Consalvi, Combust. Sci. Technol. (2018), DOI: 10.1080/00102202.2018.1452395 
8. C. Galletti, M. Lenzi, A. Parente, L. Tognotti, 29th Meeting on Combustion (2006)

9. P.A. Nooren, M. Versluis, T.H. van der Meer, R.S. Barlow, J.H. Frank, Appl. Phys. B 71, 95 (2000), DOI: 10.1007/s003400000278

10. J.D. Moore, G.T A. Risha, K.K. Kuo, M. D. D'Agostini, Combust. Sci. Technol, 177, 2069 (2005), DOI: 10.1080/00102200500240265

11. M.T. Lewandowski, P.M. Pluszka, J. Pozorski, Int. J. Numer. Method. H, (2017), DOI: 10.1108/HFF-02-2017-0078

12. P. Lappas, R.L. Evans, Int. J. Engine. Res, (2006), DOI: 10.1243/14680874JER00906

13. P.S. Kolhe, A.K. Agrawal, Flow Turbulence Combust, 79, 343 (2007), DOI: 10.1007/s10494-007-9098-y

14. B.-H. Jeon, J.H. Choi, J. Mech. Sci. Technol, 24, 1537 (2010), DOI: 10.1007/s12206010-0406-4

15. A. Najafi-Yazdi,L. Mongeau, 19th AIAA/CEAS Aeroacoustics Conference (2013), DOI: 10.2514/6.2013-2198

16. P. Satrio, R. Adityo, R. Agung, Y.S. Nugroho, IOP Conf. Ser.: Earth Environ. Sci., 105, 012085 (2018), DOI: 10.1088/1755-1315/105/1/012085

17. H. Eickhoff, A. Winandy, R. Natarajan, Experiments in Fluids, 7, 420 (1989)

18. R.W. Davis, E.F. Moore, L.-D. Chen, W.M. Roquemore, V. Vilimpoc, L.P. Goss, Theoret. Comput. Fluid Dynamics, 6, 113 (1994)

19. A. N. Lipatnikov, J. Combust, 737914 (2011), DOI:10.1155/2011/737914

20. V.K. Baev, V.A .Yasakov, Combustion, Explosion and Shock Waves, 11, 143 (1975)

21. N.J. Moore, J.L. McCraw, K.M. Lyons, International Journal of Reacting Systems, 461059 (2008), DOI:10.1155/2008/461059

22. O.A. Evdokimov, A.I. Guryanov, S.A. Piralishvili, S.V. Veretennikov, M.M. Guryanova, Journal of Engineering Physics and Thermophysics, 91, 1205 (2018)

23. J. Shi, J. Ran, C. Qin, L. Zhang, Fuel, 162, 313 (2015), DOI: 10.1016/j.fuel.2015.09.004

24. M. Rimar, A. Kulikov, AIP Conference Proceedings, 1745, 020051 (2016); DOI: $10.1063 / 1.4953745$

25. O.A. Hrihoriev, M.M. Kologrivov, Energy saving. Power engineering. Energy audit, 2(145), 2-13 (2016)

26. G.A. Evseev, Energy saving and water treatment, 45, 54 (2007)

27. O.A. Evdokimov, S.A. Piralishvili, S.V. Veretennikov, A.I. Guryanov, J. Phys.: Conf. Ser. (to be published) 